\title{
Ways of heat losses reduction in the structural elements of unique buildings
}

\author{
Alexey Kochev ${ }^{1}$, Kirill Lushin ${ }^{2 *}$, Mikhail Sokolov ${ }^{1}$,Elena Kocheva ${ }^{1}$ and Marina Kocheva ${ }^{1}$ \\ ${ }^{1}$ Nizhniy Novgorod State University of Architecture and Civil Engineering, Ilyinskaya St., 65 Nizhniy \\ Novgorod, Russia, 603950 \\ ${ }^{2}$ Moscow State University of Civil Engineering, Yaroslavskoye shosse, 26, Moscow, Russia, 129337
}

\begin{abstract}
In this article the results of theoretical and experimental studies of the reduction of heat losses in the elements of external enclosing structures of under construction, reconstructed, reconstructed and currently operated unique buildings (monuments of history and architecture) presents.
\end{abstract}

Key words: Constructive elements, Unique buildings, Reduction of heat losses, Microclimatic conditions, Historical and architectural monuments, Heat resistance

\section{Introduction}

The rational energy use and energy saving in buildings with historical and artistic value is possible only if creation and maintenance of the specified microclimate parameters are exactly matched seasonal heat balances, characteristics of the heat supply, heating and ventilation systems, required heat resistance of the enclosing structures and their elements [1].

Many of the ancient unique buildings that are monuments of history and architecture in regions with a design outdoor air temperature $\left(\mathrm{t}_{\mathrm{H}}\right) \leq-25{ }^{0} \mathrm{C}$ have basically a single-layered construction of clay brick walls with a wall thickness $\left(\delta_{\text {ст }}\right)$ more than 1 meter [2].

\section{Researches}

Significant impact on heat loss and the formation of a comfortable environment in the premises have structural elements, in which regions of two-dimensional and threedimensional temperature fields are formed: joints of walls and ceilings, external corners, window esconsons $[1,3]$. The temperature field of the outer wall near the window openings changes markedly. The thicker the wall and the smaller the distance between the window sashes, the more significant this change is (Fig. 1 and Fig. 2).

\footnotetext{
* Corresponding author: LushinKI@mgsu.ru
} 


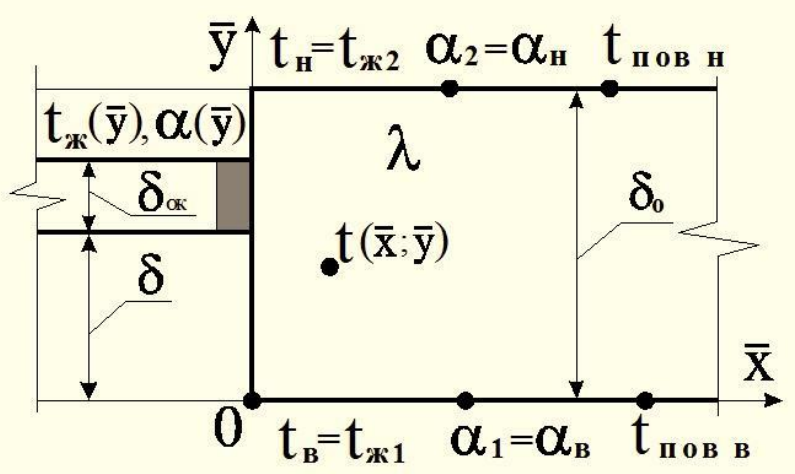

Fig. 1. The scheme of the calculation field of research.
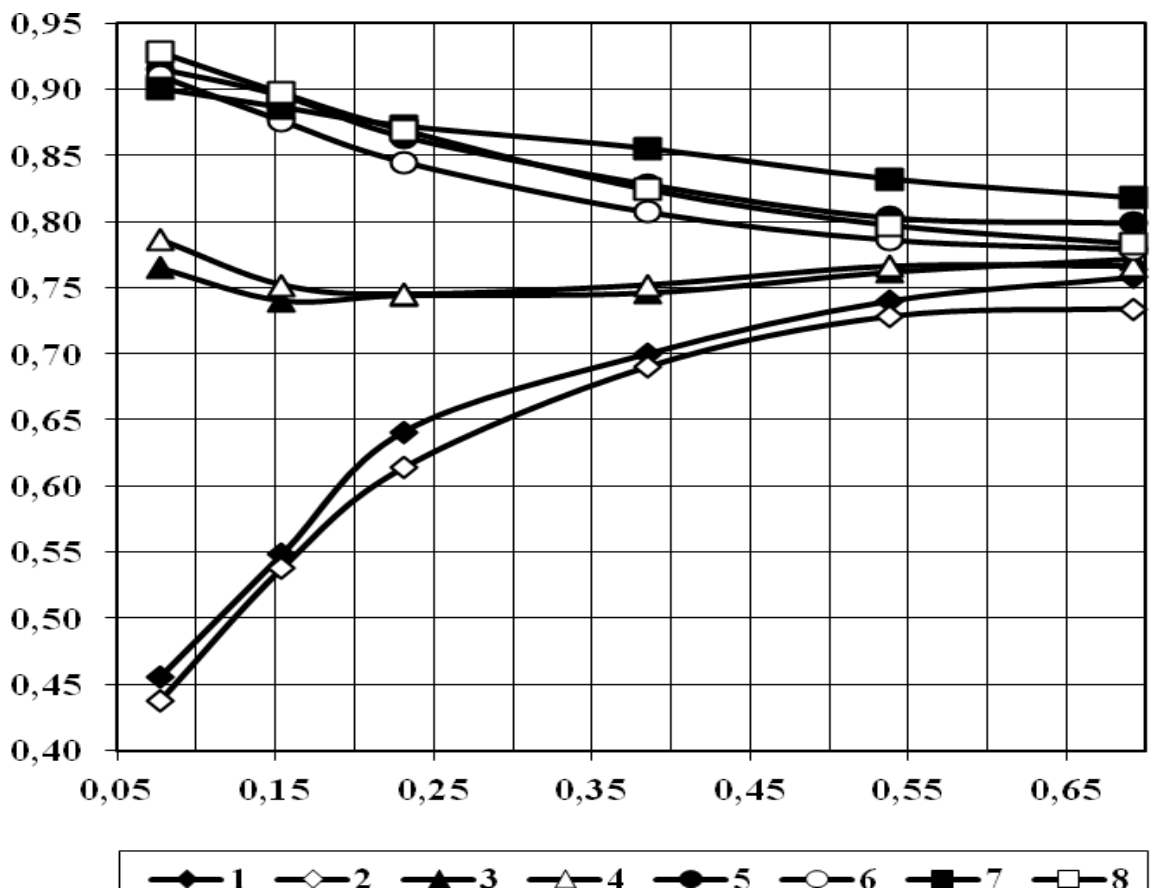

Fig. 2. Dependence of the relative temperature $\theta(\mathrm{x}, \mathrm{y})$ on the $\mathrm{x}$-coordinate at $\mathrm{T}_{ж 1}=14{ }^{\circ} \mathrm{C}, \mathrm{T}_{ж 2}=-15^{\circ} \mathrm{C}$ : $1-\mathrm{y}_{1}=0,038$ (calculation); $2-\mathrm{y}_{1}=0,038$ (experiment); $3-\mathrm{y}_{1}=0,231$ (calculation); $4-\mathrm{y}_{1}=0,231$ (experiment); $5-\mathrm{y}_{1}=0,5$ (calculation); $6-\mathrm{y}_{1}=0,5$ (experiment); $7-\mathrm{y}_{1}=0,769$ (calculation); 8 $\mathrm{y}_{1}=0,769$ (experiment).

The study of the temperature regime of window esconsons of ancient unique buildings depending on the temperatures of the external and internal air, the thickness of the wall, the design of the window sash, the position of the window sash relative to the longitudinal axis of the wall is one of the directions for solving the problem of efficient use of thermal energy 
in the under construction, Restored and reconstructed ancient unique buildings. The received results can be considered at building and operation of buildings of any purpose.

The problem of finding the stationary temperature distribution in the two-dimensional computational domain, including the part of the window and the wall esconson, was solved by the method of finite differences using the establishment method with the realization of the implicit scheme $[1,3]$.

According to the results of the study of the thermal regime of glazing and window esconsons, the tasks of reducing heat losses and reducing the width of the plane of possible condensation on the surface of window esconsons are solved.

Based on the theoretical and experimental studies carried out, as well as a comparative analysis of the results, we developed the software product «Otkos» («Esconson»), which allows us to find the rational position of the window sash relative to the longitudinal axis of the wall for different wall thicknesses and window blocks, from the condition of minimum width of the possible condensation plane on the surface of the esconson $[1,3]$.

The loss of heat through the window esconsons of churches is suggested to be calculated taking into account the coefficient of additional heat transfer $\Delta \mathrm{K}$. The coefficient of additional heat transfer of the window $\Delta \mathrm{K}$ is determined by the formula:

$$
\Delta \mathrm{K}=\mathrm{q}_{\mathrm{w}} \cdot \frac{\mathrm{p}}{\mathrm{F}}
$$

where $\mathrm{q}_{\mathrm{w}}$ - Specific (additional) heat flow through the window esconson, Watt /(meter $\left.{ }^{0} \mathrm{C}\right)$;

$\mathrm{P}$ - perimeter of the window opening, meter;

$\mathrm{F}-$ area of the window opening, meter ${ }^{2}$.

Theoretical and experimental studies of $\mathrm{q}_{\mathrm{w}}$ were carried out depending on the temperature of the internal $\left(\mathrm{t}_{\mathrm{B}}\right)$ and the external air $\left(\mathrm{t}_{\mathrm{H}}\right)$, the thickness of the wall $\left(\delta_{\mathrm{o}}\right)$ and the position of the double window wooden binding with a thickness of $\delta_{\text {or }}=0,15$ meter relative to the longitudinal axis of the wall $\bar{\delta}=\frac{\delta}{\delta_{0}}$.

This dependence is most significant for comparable sizes of the width of the standard window opening with the thickness of the fence $\left(\delta_{0}\right)$.

The value of the specific additional heat loss through the window esconson $\left(\mathrm{q}_{\mathrm{w}}\right)$ is determined from the results of the studies in a graphic form (Fig. 3 and Fig. 4).

With periodic exposure to natural factors for a long time, materials are aging, leading to a change in the strength characteristics and temperature stresses of the supporting structures $[2,3]$.

An important role in the durability of ancient buildings is played by a minimum change in the temperature of the internal air during periodic exposure to radiant and convective heat fluxes during the year.

Electroosmotic devices are used to protect buildings and monuments of ancient architecture from moisture, as well as for faster drying of enclosing structures $[4,5]$

Under the influence of water, carbon dioxide, temperature fluctuations in the wall material, various physicochemical processes take place that lead to waterlogging of structures and deterioration of their heat-shielding properties. This changes the ion composition, which increases the water-retaining capacity of the walls, which favors the formation of fungi and the development of microorganisms.

In this regard, the moisted enclosing structures of historical monuments and ancient architecture are subject to mandatory dehumidification, as this saves them from premature 
destruction and loss of bearing capacity, and also helps maintain the required microclimatic conditions for the effective preservation of structural elements and finishes $[5,6]$.

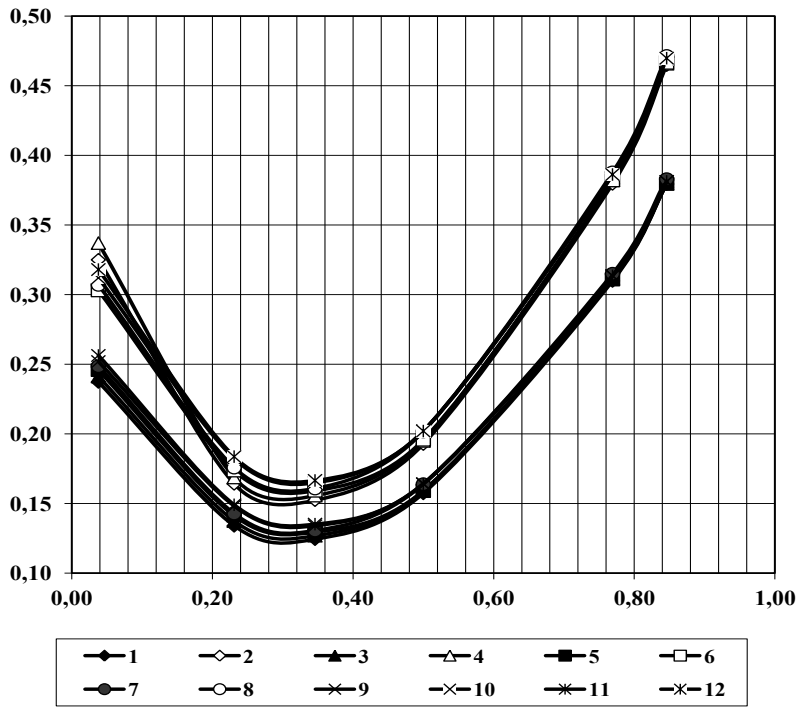

Fig. 3. The results of theoretical (odd figures) and experimental (even numbers) studies of the value of the specific additional heat loss through the window esconson $\left(\mathrm{q}_{\mathrm{w}}\right)$ as a function of the internal air temperature $\left(\mathrm{t}_{\mathrm{B}}\right)=14{ }^{\circ} \mathrm{C}$ and the external air temperature $\left(\mathrm{t}_{\mathrm{H}}\right)$ from $-8{ }^{\circ} \mathrm{C}$ till $-30{ }^{\circ} \mathrm{C}$, wall thickness $\left(\delta_{\mathrm{o}}\right)=1,04$ meter and the position of a double window wooden binding of thickness $\left(\delta_{\mathrm{o}}\right)=0.15$ meter in relation to the longitudinal axis of the wall $\bar{\delta}=\frac{\delta}{\delta_{0}}$.

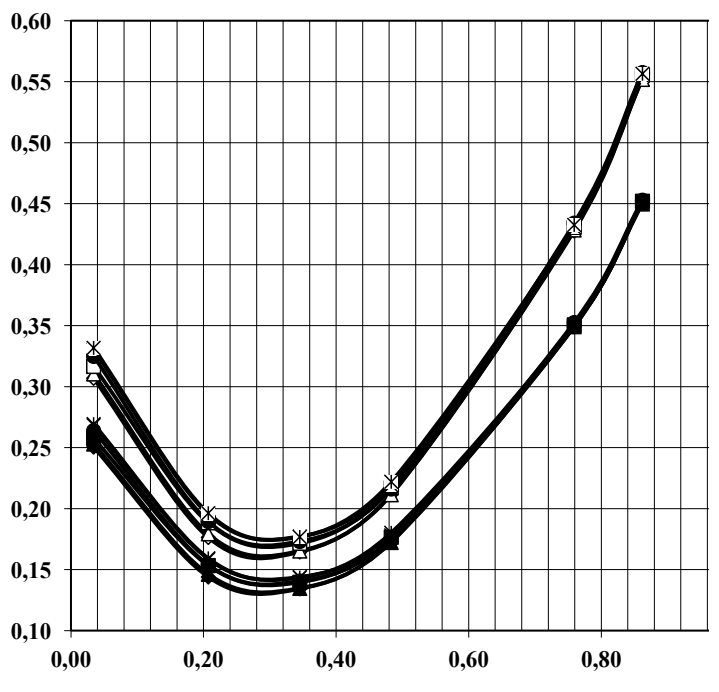

Fig. 4. The results of theoretical (odd figures) and experimental (e-ven numbers) studies of the value of the specific additional heat loss through the window esconson $\left(\mathrm{q}_{\mathrm{w}}\right)$ as a function of the internal air temperature $\left(\mathrm{t}_{\mathrm{B}}\right)=14{ }^{\circ} \mathrm{C}$ and the external air temperature $\left(\mathrm{t}_{\mathrm{H}}\right)$ from $-8{ }^{\circ} \mathrm{C}$ till $-30^{\circ} \mathrm{C}$, wall thickness 
$\left(\delta_{\mathrm{o}}\right)=1,16$ meter and the position of a double window wooden binding of thickness $\left(\delta_{\mathrm{o}}\right)=0.15$ meter in relation to the longitudinal axis of the wall $\bar{\delta}=\frac{\delta}{\delta_{0}}$.

The electric current flowing through the wires of the closed circuit when the electroosmosis structures are dried creates around itself a magnetic field, which in turn acts on moving charged particles. "Molecular" current in the wall can be regarded as a directed motion of liquid ions. Consequently, the Lorentz force acts on each particle. The direction of the action of this force is determined by the sign of the charge carrier. The transfer of moisture in the capillaries of building materials is effected by the movement of solutions of positive ions of alkalis, acid medium and diffuse layer, hence, forces are regarded as acting on a positively charged particle moving in a magnetic field.

In a homogeneous electromagnetic field, the transfer of moisture is due to the action of not only the diffusion forces and thermal diffusion, but also the action of thermodynamic forces caused by an inhomogeneous electromagnetic field [6].

\section{Results}

As a result of electroosmotic dehumidification, moisture falls on the inner surface of the structure, with which it is removed by controlled air exchange. As a result of electroosmotic dehumidification, moisture from the fence surface evaporates into the volume of the room, from which it is removed by ventilation systems due to controlled organized air exchange [6, 7] (Fig. 5).

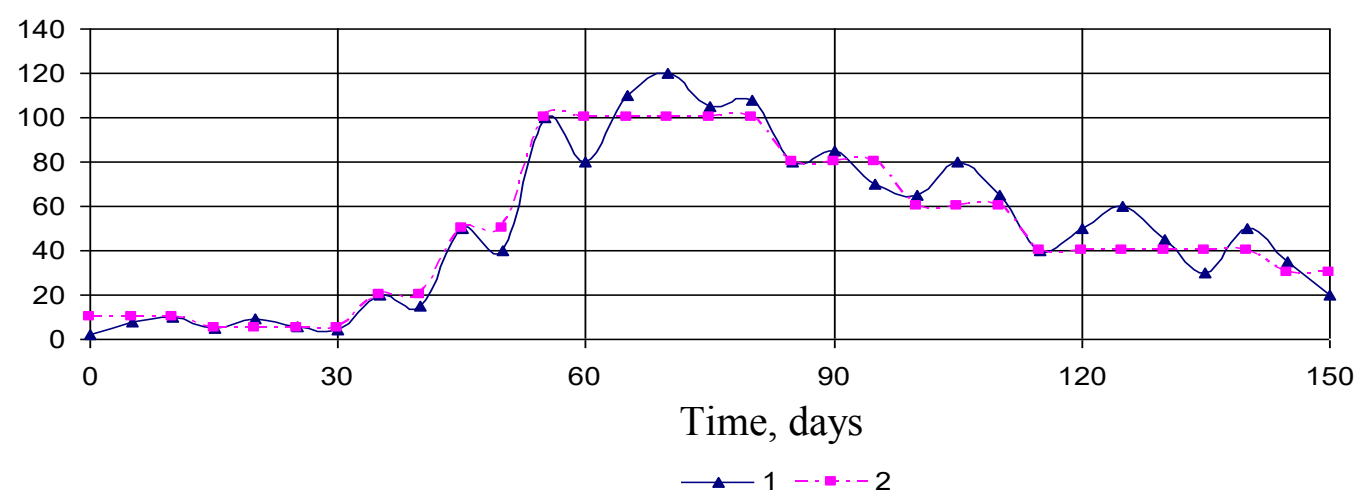

Fig. 5. Fluctuations in the air flow over the drying period, equal to 5 months: 1) theoretical calculation; 2) experimental data.

The task of ventilation is not only to remove moisture from the premises, but also to create the required microclimatic conditions in the premises and cellars of a unique building.

To ensure the required microclimate parameters in buildings that are historical and architectural monuments, it is necessary to restore or redesign heating and ventilation systems while ensuring the required thermal stability of the enclosing structures $[8,9]$.

We obtained theoretical and experimental results on automatic and manual regulation of natural ventilation, depending on the season of the year, the number of people and the power of the heating system in unique buildings. Gravitational pressure for the operation of 
ventilation is a self-regulating value in unique buildings with a dominant vertical layout [7, $8,9]$.

For each unique building we studied, which is a historical and architectural monument, individual air regulation cards were developed depending on the season of the year. Conducting energy-saving measures to regulate the air exchange of gravity ventilation (aeration) during working hours and non-working hours, can significantly reduce the heat consumption of unique buildings $[7,8,9]$.

The use of mechanical ventilation systems in buildings of historical and artistic value spoils the interior and leads to a significant increase in operating costs.

\section{Conclusions}

Unique ancient buildings, in contrast to modern buildings of general-civil purpose, have a number of design features that affect the heat and mass transfer processes in their premises

When designing natural ventilation systems in unique historical buildings, the characteristics of the climatic characteristics of the region should be taken into account.

It is recommended to calculate the natural ventilation systems for 3 calculation periods of the year: warm, transitional and cold with different occupancy of the ancient unique building by people and the characteristics of the heating system $[7,8,9]$.

The construction of natural ventilation systems should be carried out taking into account the exclusion of the formation of compact supply air streams entering the human respiration zone and the most effective removal of polluted air from the room volume by means of structural elements of the exhaust systems that do not spoil the interior and facades of the historic building.

The self-regulation of natural ventilation costs allows saving $20-50 \%$ of the heat relative to the mechanical ventilation systems analogous to the maximum air flow rates.

\section{References}

1. A.G. Kochev, Climate of the Orthodox churches: monograph (2004).

2. V.N. Kupriyanov, Designing heat insulation of enclosing structures (2011)

3. A.G. Kochev, A.S. Sergienko, Russian scientific journal, 3 (46), 285-289 (2015)

4. B.V. Matveyev, Drying walls by electroosmosis (1963)

5. O.M. Fridman, Electroosmotic method for eliminating the dampness of the walls of buildings (1971)

6. A.G. Kochev, O.V. Fedorova, M.M. Sokolov, Proceedings of universities, 2-3, 60-67 (2013)

7. AG Kochev, A.S. Sergienko, Russian scientific journal, 1 (44), 282-286 (2015)

8. M.M. Sokolov, E.A. Kocheva, M.A. Kocheva, A.S. Moskaeva, E.V. Smirnova, Scientific Review. Engineering sciences, 6., 36-38 (2016)

9. M.M. Sokolov, E.A. Kocheva, M.A. Kocheva, A.S. Moskaeva, E.V. Smirnova, Scientific Review. Engineering sciences, 6, 39-42 (2016) 